\title{
Giant gastrointestinal stromal tumor with predominantly cystic changes: a case report and literature review
}

\author{
Liying Wang ${ }^{1 *}$, Libin Liu', Zhaohui Liu', Yueli Tian and Zhe Lin²
}

\begin{abstract}
Background: Gastrointestinal stromal tumors (GISTs) rarely present with predominantly cystic changes. Here, we report a case of giant GIST of the stomach with predominantly cystic changes in a 74-year-old female patient.

Case presentation: The tumor was $10 \mathrm{~cm} \times 15 \mathrm{~cm}$ in size and positive for CD117, H-caldesmon, and DOG-1. Complete surgical resection was performed without regional lymphadenectomy. The patient recovered uneventfully and no recurrence occurred.

Conclusions: The case illustrates that GIST with cystic changes should be considered in the diagnoses of hepatic and pancreatic lesions. Furthermore, immunohistochemistry with CD117, DOG1, and other molecular markers is critical for diagnosis of GIST of the stomach and facilitates optimization of treatments for GIST.
\end{abstract}

Keywords: Gastrointestinal stromal tumor, Stomach, Cyst, Diagnosis

\section{Background}

Gastrointestinal stromal tumor (GIST) is the most common mesenchymal tumor of the digestive tract. Although GISTs only occur in less than 5\% of all gastrointestinal tract tumors, they account for $60 \%$ of all gastric stromal tumors [1]. GISTs are typically solid tumors and rarely present with predominantly cystic changes [2]. Here, we describe a case of giant GIST of the stomach with predominantly cystic changes that was cured with complete surgical resection without regional lymphadenectomy.

\section{Case presentation}

A 74-year-old female patient was hospitalized because of worsening abdominal pain for 2 days. The patient had distending upper abdominal pain for 3 months. The pain was intermittent and dull and did not radiate. She had no nausea or vomiting. Two days before admission, the pain worsened without apparent causes. The patient had no fever, and urine and stool were normal. She had no respiratory symptoms except occasional cough and whitish sputum. The patient had a history of hypertension for

\footnotetext{
* Correspondence: wangly0904@163.com

'Department of Gastroenterology, The Second Hospital of Jilin University, No. 218, Ziqiang Street, Changchun 130042, China

Full list of author information is available at the end of the article
}

5 years; the blood pressure was as high as $190 / 90 \mathrm{mmHg}$, and the patient took oral nifedipine $(30 \mathrm{mg} /$ day, sustained release tablet, Bayer).

Physical examination at admission showed tenderness in the mid and upper left abdomen, but no rebound tenderness was elicited. A mass was palpated in the upper left abdomen. The mass was approximately $10 \mathrm{~cm}$ in diameter and had an indistinct boundary and was poorly mobile. The findings were otherwise unremarkable. Laboratory findings including blood chemistries, routine blood tests, coagulation profile, and tumor markers were normal. Immunological tests for antigens or antibodies related to infections with Treponema pallidum, HIV (human immunodeficiency virus), and $\mathrm{HCV}$ (hepatitis $\mathrm{C}$ virus) were negative. Abdominal ultrasonography revealed a hypoechoic intraperitoneal mass in the upper left quadrant, $13.3 \mathrm{~cm} \times 12.5 \mathrm{~cm}$ in size, with punctate hyperechoic deposits. The wall of the cyst was rough, with many irregular hyperechoic protuberances. Abdominal CT showed a cystic hypointense shadow with septations, approximately $15.6 \mathrm{~cm} \times 14.7 \mathrm{~cm} \times 13.6 \mathrm{~cm}$ in size (Fig. 1). The stomach was compressed by the tumor and was not clearly visualized. The pancreatic gland was displaced anteriorly by the tumor, and the border between the tail of the pancreas and the tumor was indistinct. The spleen and the left kidney were displaced inferiorly by the tumor. 

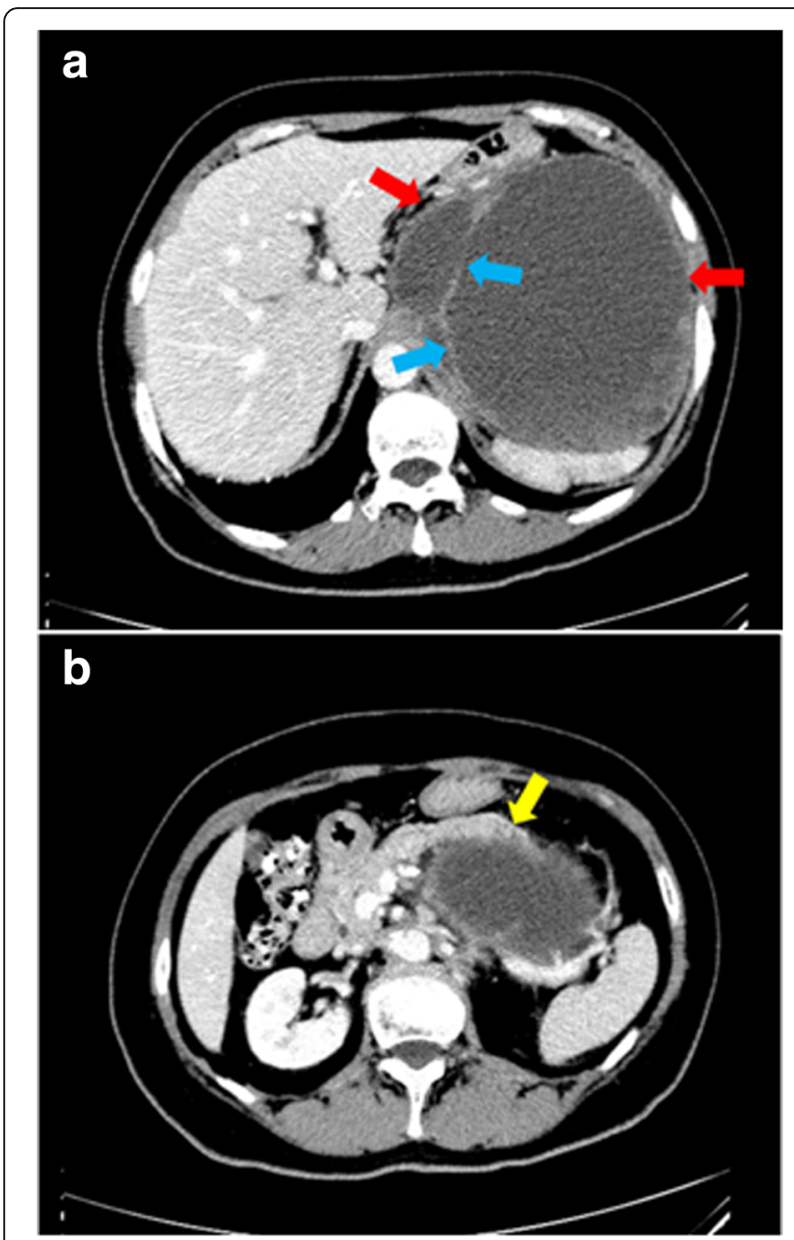

Fig. 1 Abdominal $\subset T$ demonstrates a cystic hypointense shadow in the upper left abdomen. a Septations (blue arrow) are seen in the tumor (red arrow), which is approximately $15.6 \mathrm{~cm} \times 14.7 \mathrm{~cm} \times 13.6 \mathrm{~cm}$ in size. b The pancreatic gland (yellow arrow) is compressed and displaced anteriorly, and the border between the pancreatic tail (white arrow) and the tumor is indistinct

Gastric endoscopy revealed protuberances in the fundus, suggestive of external compression.

Exploratory laparotomy showed a cystic mass in the left upper quadrant, $10 \mathrm{~cm} \times 15 \mathrm{~cm}$ in size, starting from the posterior wall of the gastric fundus and had intimate relations with the spleen and the greater curvature of the gastric fundus. Rapid pathological examination indicated gastric stromal tumors. The tumor, the proximal stomach, and the spleen were excised. The tumor had a maximal diameter of $15 \mathrm{~cm}$, with necrosis and cystic degeneration (Fig. 2). No invasion of the spleen was seen. No intraperitoneal lymph node metastasis $(0 / 3)$ and no metastasis to peritumoral lymph nodes $(0 / 6)$ were observed. Distant metastases, such as in the liver and lung, were also not observed. Postoperative pathological examination showed GIST (high grade, spindle cell variant). The mitotic index was $10 / 50$ in high-power field. Immunohistochemical study revealed CD117 (+), H-caldesmon (+), SMA (weak +), DOG-1 (+), CD34 (-), desmin (-), Ki67 (5\% positive), NSE (-), and S-100 (-). No peritoneal metastasis was present. The patient recovered uneventfully and discharged from hospital after 2 weeks. The patient received regular follow-up, and no recurrence has occurred at the time of writing this case report (20 months following surgery).

\section{Discussion and conclusions}

GISTs are the most common mesenchymal tumors and account for 0.1 to $3 \%$ of all gastrointestinal tumors [1]. GISTs had been considered to be smooth muscle neoplasms such as leiomyoma or leiomyosarcoma; subsequent studies have demonstrated that GIST arises from c-KIT (CD117)-positive intestinal cells of Cajal in the gastrointestinal tract. The clinical manifestations of GIST are non-specific and vary from being asymptomatic to abdominal pain, a palpable mass, bleeding, intestinal occlusion, and perforation. The diagnosis of GIST of the stomach is frequently not clear preoperatively, as in the current case. GISTs of the stomach with cystic changes are not common and may be misdiagnosed as hepatic or pancreatic lesions $[3,4]$. The tumor in our case had intimate relations with adjacent structures such as the liver and spleen and its border was indistinct from the pancreatic tail. Though abdominal ultrasonography, CT scan, and gastric endoscopy were performed in our patient, these diagnostic modalities failed to yield a definite diagnosis. Histologically, the tumor is composed of interlacing bundles or whorls of spindle-shaped cells. However, histological findings are noncommittal and definite diagnosis relies on immunohistochemical studies. CD117 is positive in $90 \%$ of the cases of GIST. The tumor tissue specimen in the current case was also intensely positive for CD117. Our patient was also positive for DOG1, another sensitive marker that is positive in $95 \%$ of the cases [4], but negative for CD34, which is positive in 50 to $80 \%$ of the cases [4].

One noticeable feature of our case is the presence of predominantly cystic changes in the tumor. GISTs often form solid tumors and are rarely predominantly cystic. GISTs with cystic changes are more frequently seen in high-grade malignancies. Because of aggressive tumor growth, necrosis, hemorrhage, liquefaction, and cystic degeneration occur from lack of adequate blood supply, leading to formation of large cystic spaces [5]. Necrosis and cystic degeneration were also seen in the tumor of our patient. GISTs are typically large tumors, with diameters greater than $10 \mathrm{~cm}$. Okano et al. reviewed six reported cases of GIST with cystic changes, and the size of these tumors varied from 6 to $32 \mathrm{~cm} \mathrm{[2].} \mathrm{We} \mathrm{further} \mathrm{reviewed} \mathrm{the} \mathrm{English} \mathrm{and}$ Chinese literature and summarize the reported cases 

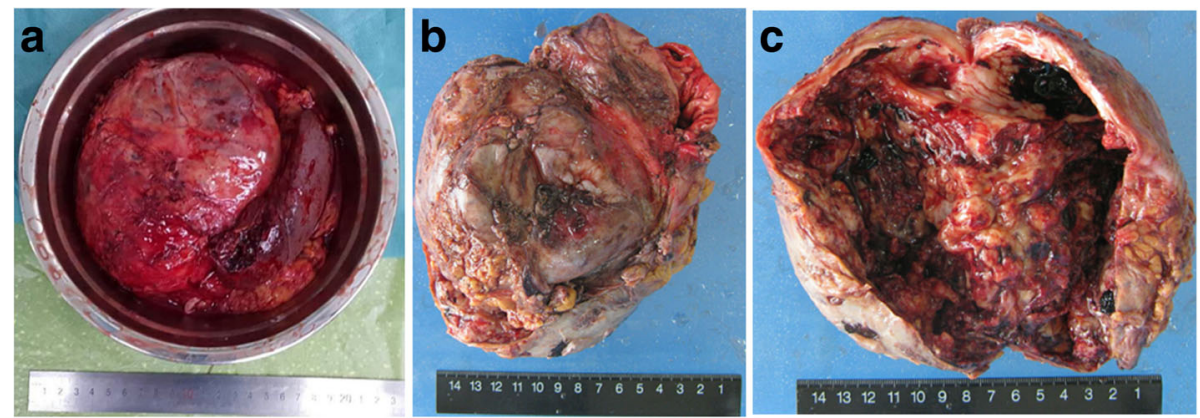

Fig. 2 a The gross appearance of the excised tumor, which is $16 \mathrm{~cm} \times 15 \mathrm{~cm} \times 13 \mathrm{~cm}$ in size. The resected tumor is well circumscribed and gray-whitish. $\mathbf{b}$ The macroscopic aspect of the resected tumor with focal areas of necrosis and cystic degeneration. $\mathbf{c}$ The irregular wall of the cyst

in Table 1 [4, 6-13]. These patients had a median age of 66 years (range 11 to 80 years) and five of them $(45.5 \%, 5 / 11)$ were female. The cyst size ranged from 6 to $37.6 \mathrm{~cm}$.

GISTs possess malignant potential and are highly invasive and tend to metastasize to remote organs [8]. Metastases of GIST commonly develop in the abdominal cavity and liver, and rarely in the lymph nodes. Though necrosis and cystic degeneration were observed in the tumor specimen of our patient, we observed no metastasis to lymph nodes and remote organs. The tumor was completely encapsulated, and invasion to adjacent tissues was not seen. This may explain that no tumor recurrence has occurred following complete surgical resection of the tumor. Wang et al. reported seven cases of GIST with cystic changes and found no recurrence 9 to 80 months following surgical resection [14].

GISTs of the stomach with cystic changes are rare and may defy diagnosis preoperatively. Our case illustrates that GIST with cystic changes should be considered in the diagnoses of hepatic and pancreatic lesions. Furthermore, immunohistochemistry with CD117, DOG1, and other molecular markers is critical for diagnosis of GIST of the stomach and facilitates optimization of treatments for GIST.

Table 1 Clinical features of reported cases of GISTs of the stomach with cystic formation in the literature

\begin{tabular}{|c|c|c|c|c|c|c|c|c|c|c|c|}
\hline Case no. & Reference & $\begin{array}{l}\text { Age, } \\
\text { years }\end{array}$ & Gender & Size, $\mathrm{cm}$ & Location & $\begin{array}{l}\text { Rupture or } \\
\text { perforation }\end{array}$ & $\begin{array}{l}\text { Mitotic } \\
\text { figures }\end{array}$ & Surgery & Imatinib & $\begin{array}{l}\text { Follow-up } \\
\text { duration, months }\end{array}$ & $\overline{\text { Recurrence }}$ \\
\hline 1 & Park et al. & 11 & $\mathrm{~F}$ & 10 & $\begin{array}{l}\text { The anterior } \\
\text { gastric wall }\end{array}$ & No & - & Yes & Yes & 9 & No \\
\hline 2 & Osada et al. & 74 & M & 12 & $\begin{array}{l}\text { The gastric wall } \\
\text { in the posterior } \\
\text { aspect of the fundus }\end{array}$ & Yes & $\begin{array}{l}\text { High } \\
\text { mitotic } \\
\text { count }\end{array}$ & Yes & Yes & 24 & No \\
\hline 3 & Cruz Jr. et al. & 37 & M & 32 & $\begin{array}{l}\text { The distal part } \\
\text { of stomach }\end{array}$ & No & $\begin{array}{l}10 / 50 \\
\mathrm{HPF}\end{array}$ & Yes & Yes & 12 & No \\
\hline 4 & Yu et al. & 80 & $\mathrm{~F}$ & 6 & $\begin{array}{l}\text { The front of } \\
\text { the stomach }\end{array}$ & Yes & $\begin{array}{l}4 / 50 \\
\mathrm{HPF}\end{array}$ & Yes & - & - & - \\
\hline 5 & Notani et al. & 58 & M & 33 & The gastric wall & No & - & Yes & Yes & 12 & No \\
\hline 6 & Zhu et al. & 78 & M & 17 & The gastric wall & No & $\begin{array}{l}>10 / 50 \\
\text { HPF }\end{array}$ & Yes & No & 36 & No \\
\hline 7 & Okano et al. & 79 & M & 60 & The gastric wall & No & $\begin{array}{l}>5 / 50 \\
\mathrm{HPF}\end{array}$ & Yes & No & 12 & No \\
\hline 8 & Colović et al. & 52 & $F$ & & $\begin{array}{l}\text { The greater curvature } \\
\text { of the stomach }\end{array}$ & No & - & Yes & Yes & 24 & No \\
\hline 9 & Chen XQ et al. & 60 & M & 28.5 & $\begin{array}{l}\text { The posterior wall } \\
\text { of the gastric body }\end{array}$ & No & - & Yes & No & 12 & No \\
\hline 10 & Yang CB & 66 & $F$ & 37.6 & $\begin{array}{l}\text { The posterior wall } \\
\text { of the gastric body }\end{array}$ & No & - & Yes & - & - & - \\
\hline 11 & The current case & 74 & $F$ & 15 & $\begin{array}{l}\text { The gastric wall in } \\
\text { the posterior aspect } \\
\text { of the fundus }\end{array}$ & No & $\begin{array}{l}>10 / 50 \\
\mathrm{HPF}\end{array}$ & Yes & No & 20 & No \\
\hline
\end{tabular}




\section{Abbreviations}

GISTs: Gastrointestinal stromal tumors; HCV: Hepatitis C virus; HIV: Human immunodeficiency virus

\section{Funding}

No funding was received for this study.

\section{Availability of data and materials}

All data and materials on which the conclusions of the paper rely be presented in the main paper.

\section{Authors' contributions}

LW designed the study and reviewed manuscript. LL data collection. ZhL Organize the cases and participate in the collection of partial data. YT operator. ZL drafted the manuscript. All authors read and approved the final manuscript.

\section{Ethics approval and consent to participate}

Not applicable.

\section{Consent for publication}

Informed consent for publication was obtained from the patient.

\section{Competing interests}

The authors declare that they have no competing interests.

\section{Publisher's Note}

Springer Nature remains neutral with regard to jurisdictional claims in published maps and institutional affiliations.

\section{Author details}

'Department of Gastroenterology, The Second Hospital of Jilin University, No. 218, Ziqiang Street, Changchun 130042, China. ${ }^{2}$ Department of Gastrointestinal Nutrition and Hernia Surgery, The Second Hospital of Jilin University, Changchun, China.

Received: 11 September 2017 Accepted: 23 November 2017

Published online: 13 December 2017

\section{References}

1. Miettinen $M$, Lasota J. Gastrointestinal stromal tumors: review on morphology, molecular pathology, prognosis, and differential diagnosis. Arch Pathol Lab Med. 2006;130:1466-78.

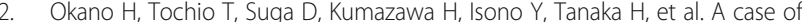
a stomach gastrointestinal stromal tumor with extremely predominant cystic formation. Clin J Gastroenterol. 2015:8:197-201.

3. Hansen Cde A, Jose FF, Caluz NP. Gastrointestinal stromal tumor (GIST) mistaken for pancreatic pseudocyst_case report and literature review. Clin Case Rep. 2014;2:197-200.

4. Zhu CC, Liu Y, Zhao G. Exophytic gastrointestinal stromal tumor with cystic changes: a case report. Oncol Lett. 2014;7:1427-9.

5. Levy AD, Remotti HE, Thompson WM, Sobin LH, Miettinen M Gastrointestinal stromal tumors: radiologic features with pathologic correlation. Radiographics 2003;23:283-304, 456; quiz 532

6. Osada T, Nagahara A, Kodani T, Namihisa A, Kawabe M, Yoshizawa T, et al. Gastrointestinal stromal tumor of the stomach with a giant abscess penetrating the gastric lumen. World J Gastroenterol. 2007:13:2385-7.

7. Park J, Rubinas TC, Fordham LA, Phillips JD. Multifocal gastrointestinal stromal tumor (GIST) of the stomach in an 11-year-old girl. Pediatr Radiol. 2006;36:1212-4.

8. Colovic R, Micev M, Matic S, Colovic N, Grubor N. Atkinson HD malignant stromal tumor of the stomach with giant cystic liver metastases prior to treatment with imatinib mesylate. Vojnosanit Pregl. 2013;70:225-8.

9. Cruz RJ Jr, Vincenzi R, Ketzer BM, Cecilio AL. Cepeda LA spontaneous intratumoral bleeding and rupture of giant gastric stromal tumor $(>30 \mathrm{~cm})$ in a young patient. World J Surg Oncol. 2008;6:76.

10. Notani H, Kawamura T, Sato T, Hoshino A, Sato Y, Nakajima A. A case of a giant gastrointestinal stromal tumor of the stomach with extramural growth. Gan To Kagaku Ryoho. 2013;40:2179-81.
11. Yu CC, Wu CC, Hwang Jl, Wang J, Chang CS. Thick calcification from a GIST of the stomach penetrating into pericolic soft tissue-report of a case. World J Surg Oncol. 2011;9:45.

12. Chen XQ, Lv HZ, Ye XY, Zhang WH, Zhang F, Zhang S. Diagnosis and treatment of huge gastrointestinal stromal tumor combined with large inguinal hernia. Chinese Journal of Digestive Surgery. 2013;12:475-6.

13. Yang CB, Jia YY, Yu Y, He TP, Duan HF, Zhang XR, et al. Giant cystic gastric stromal tumor with large external cavity growth: case report. Chinese Journal of Medical Imaging Technology. 2015;31:1448-9.

14. Wang CZ, Hou YY, Shen KT, Wang HS, Qin J, Sun YH, et al. Clinicopathological features and prognosis of cystic gastrointestinal stromal tumor. Zhonghua Wei Chang Wai Ke Za Zhi. 2011;14:599-602.

\section{Submit your next manuscript to BioMed Central and we will help you at every step:}

- We accept pre-submission inquiries

- Our selector tool helps you to find the most relevant journal

- We provide round the clock customer support

- Convenient online submission

- Thorough peer review

- Inclusion in PubMed and all major indexing services

- Maximum visibility for your research

Submit your manuscript at www.biomedcentral.com/submit 